\title{
Information Literacy Competences of LIS-Students in Switzerland - a Case Study
}

\author{
Eliane Blumer ${ }^{1}$, Jasmin Hügi ${ }^{1}$, Bernard Bekavac ${ }^{2}$, René Schneider ${ }^{1}$ \\ ${ }^{1}$ Haute Ecole de Gestion, 7, route de Drize, CH-1227 Carouge. \\ \{First Name.Last Name\}@hesge.ch \\ ${ }^{2}$ Hochschule für Technik und Wirtschaft, Pulvermühlestrasse 57, CH-7004 Chur. \\ bernard.bekavac@htwchur.ch
}

\begin{abstract}
This paper analyzes the information literacy competences of Swiss Library and Information Science students, in the context of the international Information Literacy Survey, supervised by the Department of Information Science at Hacettepe University of Ankara. The study has been conducted by the Department of Information Science at the University of Applied Sciences in Geneva in collaboration with the Information Science Department at the University of Applied Sciences in Chur.
\end{abstract}

Keywords: Information Literacy, Library and Information Science, different cultures, Switzerland

\section{Introduction}

In today's information society, we experience an information deluge, not only concerning scientific content, but also concerning news or entertainment. Therefore, it is becoming increasingly important for everybody to acquire competences in information literacy. Information literacy in this context means "the ability to handle information efficiently and competently as a result of having specific expertise, and being able to structure and select data to meet requirements. It is the ability to localize, evaluate and use information."[1]

In Switzerland, the discussion about information literacy (IL) has led not only to development on a national level, such as "Strategy of the Swiss state for an Information Society in Switzerland" [2] but also on a more concrete level with the development of the Swiss Standards of Information Literacy [3].

Especially, for students in Library and Information Science (LIS) in Switzerland, information literacy competences represent essential skills for their work life, as the role of teaching information literacy is attributed to librarians. In Switzerland, there are two universities of Applied Sciences which offer bachelor's and master's degree in library and information science (LIS) and which teach different aspects of information literacy, e.g. search on the web, search in data bases, citations etc. 
This article puts a special focus on the information literacy competences of LIS students in Switzerland with the assumption that their proficiency augments the more they advance in their studies.

\section{Information Literacy of Library and Information Science Students - Swiss Case Study}

The Department of Information Science at Hacettepe University in Turkey has started an international survey of information literacy among LIS students. The two universities of Applied Sciences (HEG Geneva and HTW Chur) participated in this study. In this article, the results regarding Switzerland are presented.

Until now, there has been little research directly concerning information literacy of LIS students. Therefore, this is the first study which sheds some light on the situation in Switzerland.

The main interest of this research is the development of information literacy skills of LIS students during their studies. As throughout the three years of the bachelor studies, many courses regarding search, localization, evaluation and citation are given, the information literacy skills should gradually improve.

In order to be able to analyze this improvement statistically, the questions of the survey have been mapped to the Swiss standards of information literacy - information need, retrieval, assessment, organization, application and responsibility within information society [2]. Four of these standards were chosen for our research questions.

RQ1: To what degree do students get more proficient in information retrieval during their studies?

RQ2: To what degree does the information need analysis improve during their studies?

RQ3: To what degree does the responsibility within an information society improve during their studies?

RQ4: To what degree do students get more proficient in information organization during their studies?

\subsection{Methodology}

As stated before, the authors of this paper have participated in a larger, international study of information literacy. Therefore, the method to apply has been chosen in the larger research group, which has decided to use an online survey for this undertaking. For this, a common questionnaire has been established. Every participant could then translate the questionnaire in the language of his or her respective country and was free to add additional questions for their own research interests.

For the survey in Switzerland, the questionnaire has been translated in French and in German. The French translation was done jointly with the participant from France, whereas the German translation has been established by the Information Science 
Department of the University of Applied Sciences in Geneva. Several questions were adapted to the Swiss context, but no additional questions have been added.

The survey was sent in December 2012 to 290 Bachelor students. The call for participation was sent by mail to the student's mail account at their university and the survey has been accessible during three months. The start date was in the beginning of November and the survey stayed open until the end of January. These dates converge with the end of the winter semester. Therefore, the students of the first bachelor year were at the end of their first semester, the students of the second year were at the end of their third semester and the students of the third year were at the end of their fifth semester.

Concerning the current study, it is important to note that a convenience sampling method has been used. Therefore, the findings of this study are not representative for the basic population (e.g. all LIS bachelor students), but refer only to this sample. Consequently, generalizations cannot be drawn out of this study, but only to the here analyzed sample.

For every research question, a different number of items from the survey have been selected and analyzed in relationship to the Bachelor year the students are in. To do so, a Spearman's rho correlation has been used in all cases. Due to limited place in this paper, the results of these tests are only mentioned when the results had a significance of $\mathrm{p} \leq 0.05$.

\section{Findings}

Totally, 79 responses have been collected, of which 26 have been incomplete and which were therefore excluded of the analysis. Of the 53 complete surveys, the answers of three participants are not taken into consideration for statistical evaluation because they are studying part time. As their studies last for four years instead of three, the corresponding semester to the normal curriculum cannot be determined and therefore cannot be compared to fulltime students. The other 50 answers are complete and have been used for statistical analysis and review. Compared to the basic population (290 students), the response rate is of $17 \%$.

\subsection{Demographics}

Of the 50 undergraduate students who participated in the study, $88 \%$ were female and $12 \%$ were male. There is a nearly equal representation of each bachelor year, with $30 \%$ (15 participants) in the first year, 34\% (17 participants) in the second year and $36 \%$ (18 participants) in the third year. Concerning the two universities whose students have been asked to participate, the number of participants is exactly the same, namely $25(50 \%)$. 


\subsection{RQ1: To what Degree Do Students Get More Proficient in Information Retrieval during Their Studies?}

Table 1. Items used for the dimension Information Retrieval

\begin{tabular}{l}
\hline Dimension Information Retrieval \\
Finding the appropriate database is difficult \\
Finding the appropriate article within a database is difficult \\
Frequency of use of databases
\end{tabular}

Only the dimension "Frequency of use of databases" shows a statistical significance $(p=0.006)$, with a low, positive correlation $\left(r_{s}=0.381\right)$, whereas the other two dimensions are not significant.

The knowledge about the existence of scientific databases within a certain field of interest, as well as an introduction into the use of these systems, is something a Bachelor student learns during his studies in Library and Information Science. As the papers which the students have to write during their studies become more complex and necessitate increasingly the use of data bases for gathering background information, the frequency of use rises until the end of the Bachelor.

The answers regarding the difficulty of finding an appropriate data base seem more scattered. Of the 48 participants giving an answer, 33\% did agree having some difficulty with this task, while $23 \%$ marked the neutral category and $43 \%$ did disagree with the statement.

However, the statement about the difficulty of finding an appropriate article within a database was disagreed with by $56 \%$ of the 46 respondents, whereas the neutral and the agreeing category were each chosen by $22 \%$ of the participants. It seems that for this sample, it is more difficult to find the appropriate database than to search within the database. The most obvious interpretation of this result is that once the right database is found, it is easy to find relevant articles to a specific topic. Or a database is only regarded as appropriate if relevant articles were found in it.

\subsection{RQ2: To what Degree Does the Information Need Analysis Improve During Their Studies?}

Table 2. Items used for the dimension Information Need Analysis Correlations between bachelor year and research strategies

Dimension Information Need Analysis

Difficulty to develop a search strategy

Finding keywords

Creation of a research plan

Change of keywords after unsuccessful search

Acquiring knowledge about scientific research of information is one of the most important parts of the LIS-curriculum and its success should be seen as obligation for 
every LIS-faculty. In the current case, no statistical significance can be seen at all. This could be due to the small sample, which would mean that a test with a bigger sample should be done concerning LIS-Students research strategies.

Another possibility could be that students already know the important basics about research strategies when starting their studies and therefore acquire only a little more knowledge about this issue. In Switzerland, it is required to have made an internship of twelve months or an apprenticeship of three years in an organization linked to the LIS field prior to starting the bachelor studies in LIS. Therefore, some basic knowledge in research strategies may be acquired before starting at the university.

Generally, it can be said that the students regardless their current semester don't estimate to have a difficulty creating a search strategy ( $48 \%$ of disagreement with the statement) and do often make a planning for their search $(26 \%$ marked very often and $30 \%$ marked often). $46 \%$ of the participants indicated that their first activity for a search often consists of finding appropriate keywords whereas they change their keywords a little less frequently after an unsuccessful search (34\% often and $42 \%$ indicated sometimes).

\subsection{RQ3: To what Degree Does the Responsibility within an Information Society Improve during Their Studies?}

Table 3. Items used for the dimension Responsibility within Information Society

Dimension Responsibility within Information Society

Difficulty to know when to cite a source

Difficulty to know to cite in the correct format

Difficulty to know when it is plagiarism or not

The first two analyzed dimensions don't have a statistical significance. There is no statistically relevant improvement regarding the citation behavior of LIS-students by comparison of the three bachelor years.

Regardless of the current semester of the students, the results show that the students estimate that they have no difficulty to know when they have to cite a source (62\% disagreed with the statement, $20 \%$ marked the neutral category and $18 \%$ agreed with the statement). The statement about the difficulty to know the correct format to cite in showed similar results $(64 \%$ disagreed, $10 \%$ marked the neutral category and $26 \%$ agreed with the statement).

The last dimension is statistically significant $(p=0.047)$ and there is a low negative correlation between the two elements $\left(r_{s}=-0.288\right)$. It is a fact that the more LISStudents advance in Bachelor courses the more they learn about citation and therefore are more aware of plagiarism problems, because they have to write a bachelor thesis in the sixth semester in order to accomplish their undergraduate studies. 


\subsection{RQ4: To what Degree Do Students Get More Proficient in Information Organization during Their Studies?}

Table 4. Items used for the dimension Information Organization

Dimension Information Organization Frequency of use of bibliographic tool

The question regarding the frequency of use of a bibliographic tool (like Zotero or Endnote) caused some surprise as $29 \%$ indicated that they never use a bibliographic tool. This result was not expected as these tools are shown and explained in classes early during the bachelor studies. It seems that they don't represent an advantage to LIS students and are therefore not used as much.

\section{Difficulties of LIS Students}

In table 5, the analyzed dimensions of the Swiss IL-standards are shown with its studied items. Each item has an evaluation derived from the auto-evaluation from the participants of the survey. When the overall result of all answers was positive, the label "Good" is put in the table. When the overall result was negative, the item is labeled with "Bad". When the results were highly mixed, the label mixed was put. Table 5 shows that LIS-students in Switzerland have a rather good level of IL. Seven out of 11 of the evaluated items have the label "Good". Two items were stated as mixed and another two items as bad. The biggest problems apparently remain within the first standard (information need), where the creation of a research plan is realized rather rarely. Within the same standard, the change of keywords is an activity which the respondent LIS students either carry out very often or very rarely. The fourth standard (information organization), where the item "use of a bibliographic tool" has been placed, seems to be problematic as well. Most of the survey participants make seldom use of a bibliographic tool. This seems rather surprising as the importance of using those tools is explained more than once during the studies.

Table 5. Swiss Information Literacy Standards Mapping

\begin{tabular}{lll}
\hline Information need & $\begin{array}{l}\text { Difficulty to develop a search strategy (RQ2) } \\
\text { Finding keywords (RQ2) } \\
\text { Creation of research plan (RQ2) } \\
\text { Change of keywords after unsuccessful search (RQ2) }\end{array}$ & $\begin{array}{l}\text { Good } \\
\text { Good } \\
\text { Bad } \\
\text { Information retrieval }\end{array}$ \\
& $\begin{array}{l}\text { Finding the appropriate database is difficult (RQ1) } \\
\text { Finding the appropriate article within a database is } \\
\text { difficult (RQ1) } \\
\text { Frequency of use of databases (RQ1) }\end{array}$ & $\begin{array}{l}\text { Mixed } \\
\text { Good }\end{array}$ \\
& $\begin{array}{ll}\text { Use of bibliographic tool (RQ3 ) } \\
\text { Information organization }\end{array}$ & Bad
\end{tabular}




\section{Conclusion}

This study aimed to analyze the information literacy competences of information science students within two University of Applied Sciences in Switzerland, assuming that their proficiency increases the more students advance in their studies. To verify this assumption, four research questions, which all map to one standard of the Swiss IL-standards (on behalf of assessment and application), have been built.

In a further step, a different number of items form the survey have been selected and analyzed in relationship to the Bachelor year the students are in by using a Spearman's rho correlation. Only two of the eleven analyzed items have shown a statistical significance. This rather small number may be due to the convenience sampling as well as the small size of the sample. Therefore, it is not possible to make an overall statistically significant deduction, if the IL-level of Swiss LIS-students improves, but generally, the students don't seem to have any problems concerning IL.

In regard of the Swiss standards, the biggest problems remain within the information need and information organization standards. Here, the question has to be asked, if this is due to a not adapted IL-curriculum at the concerned Universities, because, as Milz [4] lined out in her work, generally, not all aspects of IL are taught. Another possible interpretation could be the fact that students are not able to selfevaluate properly their competences within a specific field [5].

In all cases, this paper has to be seen as a first attempt to analyze the Swiss situation of IL-competences of LIS-students. There is definitively a strong need for further research within this field and future work should be done in regard of competences of Master students of library and information science, as well as of the self-estimation of competences of students within Library and Information Science.

\section{References}

1. Swiss electronic library. Information literacy at Swiss Universities. http://elib.ch/en/Offres/Competence-informationnelle (Retrieved April 2013)

2. OFCOM. Strategy of the Federal Council for an Information Society in Switzerland 2012. http://www.bakom.admin.ch/themen/infosociety/00695/index.html?lang=de (Retrieved May 20, 2013)

3. Stalder, P. et al. (2011). Swiss information literacy standards. ttp://www.informationskompetenz.ch/doc/elib/1_e_swiss\%20information\%20literacy\%20st andards.pdf (Retrieved May 20, 2013)

4. Milz, J. : Informationskompetenz-Vermittlung an Deutschschweizer Fachhochschulen: eine quantitative Inhaltsanalyse der Curricula. Churer Schriften zur Informationswissenschaft. 37 (2010)

5. Gross, M., Latham, D. Undergraduate perceptions of information literacy: defining, attaining, and self-assessing skills. College and Research Libraries. 336-348 (2009) 